\title{
TRANSPLANTATION OF GENETICALLY MARKED CARDIAC MUSCLE CELLS
}

Satoshi Gojo, MD Soichiro Kitamura, $\mathrm{MD}^{\mathrm{a}}$ Osamu Hatano, $\mathrm{PhD}^{\mathrm{b}}$ Akira Takakusu, $\mathrm{MD}^{\mathrm{b}}$ Kenji Hashimoto, $\mathrm{PhD}^{\mathrm{b}}$ Yumi Kanegae, $\mathrm{PhD}^{\mathrm{c}}$ Izumu Saito, $\mathrm{MD}^{\mathrm{c}}$
We examined the possibility that cardiomyocytes could be genetically marked or modified before being grafted to the heart under conditions applicable to the clinical setting. We used a replication-defective recombinant adenovirus carrying the $\beta$-galactosidase reporter gene, and delivered it to cultured murine fetal cardiac myocytes. Virtually all fetal cardiomyocytes in a primary culture expressed $\beta$-galactosidase 24 hours after recombinant adenovirus infection. These cells were transplanted to the hearts of syngenic adult recipient mice. Expression of the $\beta$-galactosidase gene in the grafted cells was demonstrated by staining with 5-bromo-4chloro-3-indoyl- $\beta$-D-galactosidase, resulting in a blue color at the histochemical level and an electron-dense deposit on transmission electron microscopic analysis. Gene expression was recognized from 7 days to $\mathbf{1 2}$ weeks after transplantation. Implanted cardiomyocytes aligned themselves along the layers of the host myocardium. Formation of gap junctions was demonstrated by transmission electron microscopy. Neither inflammation nor fibrous scar tissue was detectable by histologic analysis. This study demonstrates that ex vivo gene transfer to the heart by means of the adenoviral vector is possible. (J Thorac Cardiovasc Surg 1997;113:10-8)
C ardiac cell transplantation is one potential treatment for acute or chronic heart failure with a significant loss of myocardium. Until recently, however, cardiac cell transplantation has received minimal attention. Prerequisites for cellular transplantation to the heart to be successful include the following: (1) the formation of a new functional syncytium between grafted and host cardiomyocytes, (2) a number of grafted cells large enough to improve cardiac function, and (3) long-term graft survival. Cellular transplantation to the heart has been investigated primarily with transformed cell lines $^{1-4}$ and satellite cells ${ }^{5,6}$ as the donor cells. These cells usually survived for 2 months after implanta-

From the Departments of Surgery $\mathrm{III}^{\mathrm{a}}$ and Anatomy, ${ }^{\mathrm{b}}$ Nara Medical College, Nara, and the Laboratory of Molecular Genetics, ${ }^{\mathrm{c}}$ Institute of Medical Science, University of Tokyo, Tokyo, Japan.

Supported in part by a grant from the Ministry of Health and Welfare, Tokyo, Japan.

Received for publication Nov. 17, 1995; revisions requested Feb. 22, 1996; revisions received April 17, 1996; accepted for publication April 25, 1996.

Address for reprints: Satoshi Gojo, MD, Department of Surgery III, Nara Medical College, 840 Shijo-cho, Kashihara, Nara 634, Japan.

Copyright (c) 1997 by Mosby-Year Book, Inc.

$0022-5223 / 97 \$ 5.00+0 \quad \mathbf{1 2} / \mathbf{1} / 74601$ tion but did not form intercalated disks within the host myocardium. Recently, studies with transgenic mice carrying a $\beta$-galactosidase ( $\beta$-gal) transgene showed that the intracardiac grafting of fetal cardiomyocytes resulted in the formation of intercalated disks between the grafted fetal cardiomyocytes and the recipient myocardium. ${ }^{7}$ The transfer of a therapeutic gene in the cells to be grafted may possibly raise cardiac cell transplantation from an experimental study to a clinical treatment. At present, however, it is unknown whether ex vivo genetically engineered cardiomyocytes can be grafted. To examine this issue, we performed cell transplantation of the fetal myocardial cells with a recombinant adenovirus expressing the $\beta$-gal reporter gene as the gene transfer vector.

\section{Materials and methods}

Mice. All animals received humane care in compliance with the "Principles of Laboratory Animal Care" formulated by the National Society for Medical Research and the "Guide for the Care and Use of Laboratory Animals" prepared by the Institute of Laboratory Animal Resources and published by the National Institutes of Health (NIH Publication No. 86-23, revised 1985). Adult BALB/c mice were purchased from Clea Japan, Inc., Tokyo, Japan. All animals were bred and maintained in a laminar-flow rack in our animal facility. All mice were 12 to 16 weeks old when used in experiments. Mice were mated overnight, and the fertilized female mice were selected the next morning $(0.5$ embryonic day) on the basis of the presence of a vaginal 
plug. Fetuses were obtained from timed pregnancies at day 16.5 of gestation.

Adenoviral vector construction. The replication-deficient recombinant adenovirus (Adex1CALacZ) was constructed by in vivo homologous recombination in 293 cells between the expression cosmid cassette and the parental virus genome. The recombinant adenovirus was generated through a modification of the method of Saito and coworkers. ${ }^{8}$ Briefly, an expression cosmid cassette was constructed by inserting the expression unit, ${ }^{9}$ composed of the cytomegalovirus enhancer plus chicken $\beta$-actin promoter, a complementary deoxyribonucleic acid (DNA) coding sequence of a $\beta$-gal gene, and the rabbit $\beta$-globin polyadenylate signal sequence, into the $S w a I$ site of pAdex $1 w$, which is a $42 \mathrm{~kb}$ cosmid containing a $31 \mathrm{~kb}$ adenovirus type 5 genome lacking $E 1 A, E 1 B$, and $E-3$ genes (Fig. 1). The expression cosmid cassette and adenovirus DNA-terminal protein complex were cotransfected into 293 cells (ATCC; CRL1573) by calcium phosphate precipitation. Incorporation of the expression cassette into the isolated recombinant virus was confirmed by digestion with appropriate restriction enzymes. The recombinant viruses were subsequently propagated with 293 cells, and viral solution was stored at $-80^{\circ} \mathrm{C}$.

Generation of high-titer viral stocks. To prepare the adenovirus stock, a Bioruptor 200 (Cosmo Bio Co., Tokyo, Japan) was used for disrupting the infected 293 cells. Lysates of 293 cells infected with the Adex ICALacZ virus were used to reinfect 293 cells two more times. The third lysates were centrifuged through cesium chloride gradients. ${ }^{10}$ Purified virus was stored at $-80^{\circ} \mathrm{C}$ until use. The titers of the viral stocks were measured by an end-point cytopathic effect assay. ${ }^{11}$ A $50 \mu$ portion of Dulbecco's modified essential medium (D-MEM) supplemented with $5 \%$ fetal calf serum (FCS) was dispensed into each well of a 96-well tissue-culture plate. Eight rows of threefold serial dilutions of the virus, starting from a $10^{-4}$ dilution, were then prepared. Next, $3 \times 10^{5} 293$ cells in $50 \mu \mathrm{l}$ D-MEM containing 5\% FCS were added to each well. The plate was incubated at $37^{\circ} \mathrm{C}$ in $5 \%$ carbon dioxide in air, and $50 \mu \mathrm{l}$ D-MEM supplemented $10 \%$ FCS was added to each well every 3 days. Twelve days later, the cytopathic effect was determined by light microscopy and the $50 \%$ tissue-culture infectious dose $\left(\mathrm{TCID}_{50}\right)$ was calculated. One $\mathrm{TCID}_{50} / \mathrm{ml}$ corresponds to approximately 1 plaqueforming unit (pfu)/ml. In this experiment, the titer of recombinant adenovirus was $2 \times 10^{9} \mathrm{TCID}_{50} / \mathrm{ml}$.

Primary culture of murine fetal cardiomyocytes. Mouse heart ventricles were removed from BALB/c fetuses at day 16.5 of gestational age, minced, and resuspended in phosphate-buffered saline solution (PBS) containing calcium $(1.7 \mathrm{mmol} / \mathrm{L})$ and magnesium $(1.5 \mathrm{mmol} /$ L). The resultant fragments were digested with $0.06 \%$ trypsin for 5 minutes at $37^{\circ} \mathrm{C}$ in a carbon dioxide incubator with a magnetic stir bar operating at low speed. The supernatant was replaced by $0.06 \%$ trypsin in PBS without the divalent cations, and the digestion was carried out again under the same conditions. This treatment was repeated four more times. The supernatants from the second to the fifth incubations were transferred to test tubes containing cold D-MEM supplemented with $10 \%$ FCS. After centrifugation at $350 \mathrm{~g}$ for 3 minutes, the

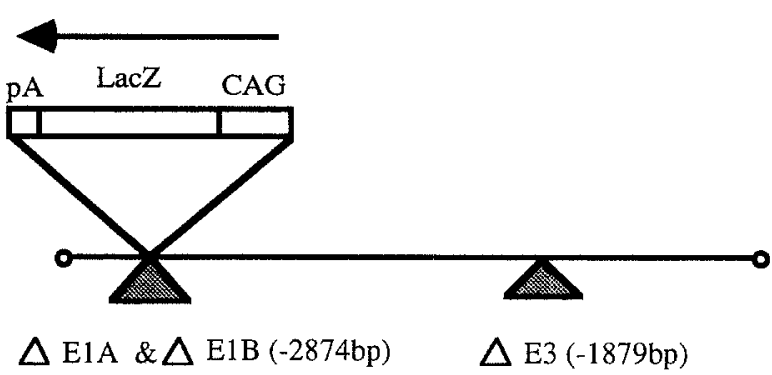

Fig. 1. Structure of $A d \operatorname{dex} 1 \mathrm{CALacZ}$ vector. In place of $E 1 A$ and $E 1 B$, an expression unit composed of chicken $\beta$-actin promoter with cytomegalovirus enhancer ( $C A G)$, $\beta$-gal gene ( $L a c Z$ ) complementary DNA, and a polyadenylate signal $(p A)$ was introduced to generate Adex 1CALacZ expression vector.

supernatant was discarded and the cells were resuspended in D-MEM containing 10\% FCS. The suspension was seeded into glass petri dishes and incubated for 1 hour at $37^{\circ} \mathrm{C}$ in $5 \%$ carbon dioxide $/ 95 \%$ air to exclude nonmyocytes. ${ }^{12}$ The supernatant and nonadherent cells were then collected and filtered through a Swinnex filter (Millipore Corporation, Bedford, Mass.) with lens paper to remove large clumps of cells. The filtered cells were seeded into 35 $\mathrm{mm}$ collagen-coated plastic culture dishes at $2 \times 10^{5}$ cells/dish. The dishes were incubated in D-MEM supplemented with $10 \% \mathrm{FCS}$ at $37^{\circ} \mathrm{C}$ in a humidified atmosphere of $5 \%$ carbon dioxide/95\% air. Almost all the myocytes attached to the culture dish and beat spontaneously after 1 day (Fig. $2, A$ ).

Infection of the adenoviral vector into cardiomyocytes. On day 1 after seeding the murine fetal cardiac cells, the cultures were incubated with $100 \mu \mathrm{l}$ AdexICALacZ virus stock at various concentrations (multiplicity of infection [MOI] of $1000,100,10,1$, or 0.1 ) and D-MEM supplemented with $10 \%$ FCS without the adenoviral vector for 60 minutes at $37^{\circ} \mathrm{C}$. The cells were washed three times to remove any virus remaining on the cell surface. The infected cells were incubated in D-MEM supplemented with $10 \% \mathrm{FCS}$ at $37^{\circ} \mathrm{C}$ in a carbon dioxide incubator for 1 day. These cells were used for 5-bromo-4-chloro-3indoyl- $\beta$-D-galactoside (X-gal) staining and cell transplantation to the heart. The creatine kinase (CK) values of the supernatant were measured 1 hour after the adenoviral infection, and the numbers of living and dead cells were also counted 24 hours after the infection to evaluate damage to the cardiac cells at various concentration of the adenovirus ( $n=5$ each group). We used $6 \mathrm{~cm}$ culture dishes seeded at $1 \times 10^{6}$ cells per dish to assess $\mathrm{CK}$ value and the numbers of alive and dead cells, because we could not detect significant increase of CK value at $2 \times 10^{5}$ cells.

$\mathbf{X}$-gal staining of cultured cardiomyocytes. One day after the adenoviral infection, the medium of the infected cultures was discarded and $1 \mathrm{ml} 0.05 \%$ glutaraldehyde was added to fix the cells. After 10 minutes of fixation, the myocytes were rinsed three times in PBS. They were then overlaid with $1 \mathrm{mg} / \mathrm{ml} \mathrm{X}$-gal with $15 \mathrm{mmol} / \mathrm{L}$ potassium ferricyanide, $15 \mathrm{mmol} / \mathrm{L}$ potassium ferrocyanide, and 2 

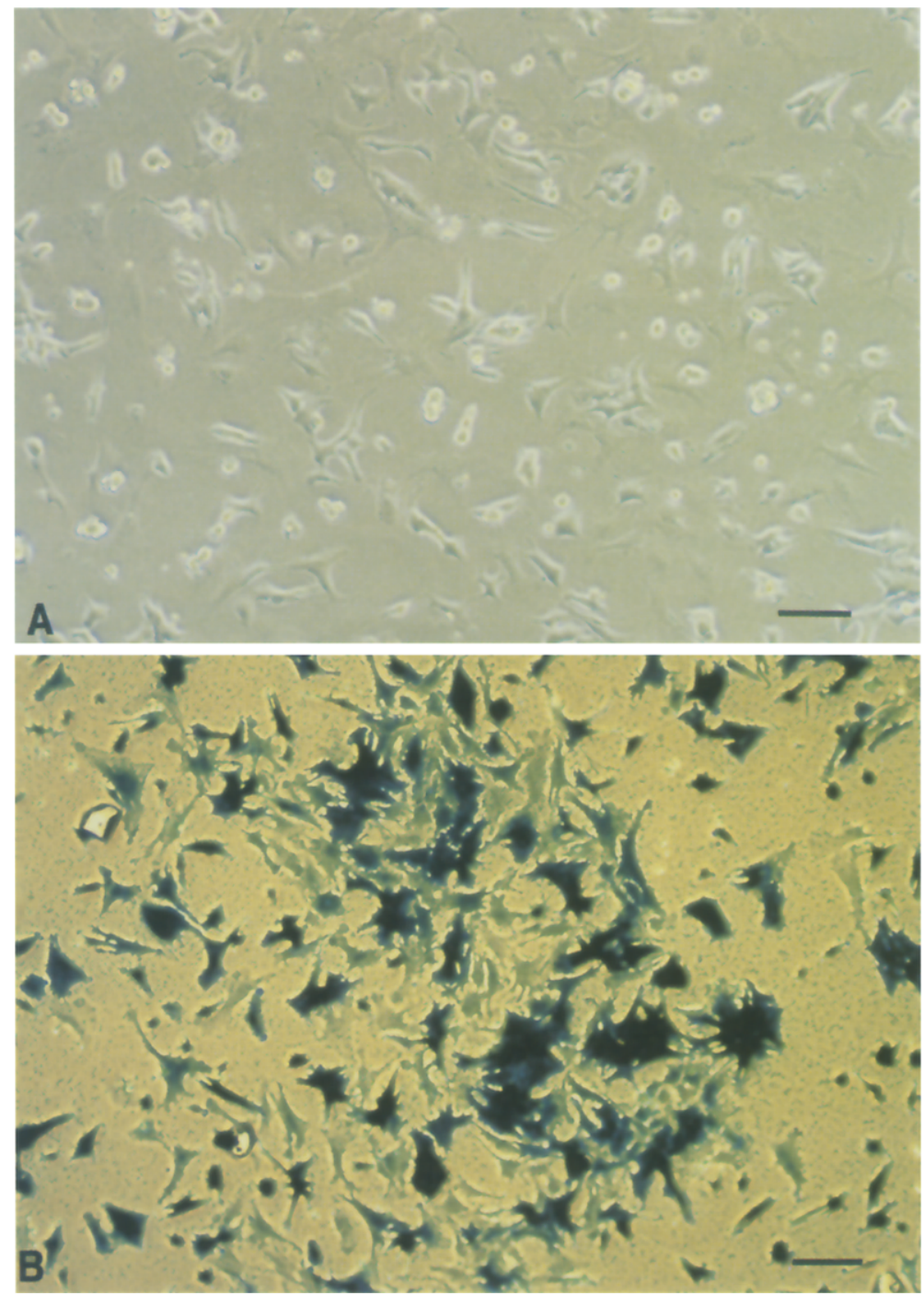

Fig. 2. X-gal staining of cultured murine fetal cardiac cells. A, Microscopic photograph of culture 1 day after cells had been plated. Approximately $90 \%$ to $95 \%$ of cultured cells in each field beat spontaneously. Beating rate in these myocytes was not uniform. Clusters, however, did beat synchronously. X-gal staining was performed 1 day after adenovirus infection. B, All cells had assays positive for $\beta$-gal showing blue color, at $10 \mathrm{MOI}$. Bars indicate $100 \mu \mathrm{m}$.

$\mathrm{mmol} / \mathrm{L}$ magnesium chloride in PBS (X-gal solution) and incubated for 1 hour at $37^{\circ} \mathrm{C}$.

Measurement of CK. CK activity in the culture medium was measured 1 hour after the adenoviral infection. ${ }^{13}$ Briefly, after mixing of the culture medium with the assay solution, the assay reaction was started by the addition of creatine phosphate. The production of reduced nicotinamide adenine dinucleotide phosphate was measured at $340 \mathrm{~nm}$.

Cell transplantation into syngenic adult mice. Cultured cells were prepared for transplantation by trypsinization, resuspension in D-MEM containing $10 \%$ FCS, and washing three times with serum-free D-MEM to avoid contamination by AdexICALacZ. The fourth resus- pension was used as the implanted cell population. The final cell density for implantation was $5 \times 10^{7}$ to $1 \times 10^{8}$ cells/ml, and the suspension was kept on ice until transplantation. Cell viability in suspension, determined by $0.05 \%$ erythrosine dye exclusion, was $90 \%$ to $95 \%$. After the initiation of general anesthesia in the recipient mice by an intraperitonial injection of $0.05 \mathrm{mg} / \mathrm{g}$ weight pentobarbiturate, a transverse incision under the arch of a rib was made. The xiphoid process was inverted to the head, and the liver was pushed inferiorly so that the heart became visible through the diaphragm. Immediately before implantation, the cell suspension was drawn up into a $10 \mu \mathrm{l}$ Hamilton syringe with a 31-gauge needle. A $10 \mu \mathrm{l}$ portion of the cell suspension was injected through the 
diaphragm directly into the ventricular myocardium of each syngenic adult recipient mouse (fetal cardiomyocytes, $n=$ 60 ). The final supernatant used for rinsing the donor cells was plated on the top of NIH 3 T3 cells, and the cells were stained with the X-gal solution 24 hours later. Moreover, 10 $\mu \mathrm{l}$ of the third supernatant or a plasmid DNA $(1 \mu \mathrm{g} / \mu \mathrm{l})$ containing the expression unit (including $\beta$-gal gene) of the adenoviral vector was injected into the ventricular myocardium of each syngenic adult mouse ( $n=10$ each). The only complication of this procedure was pneumothorax in one animal in an early experiment.

Histologic examinations of the heart. Some of the animals grafted with fetal cardiomyocytes were killed each week (five after 1 week and three each, weeks 2 to 12) after electrocardiograms were recorded for 1 hour to determine whether the cellular grafting caused any injuries to the host hearts. The hearts were dissected and fixed in $4 \%$ paraformaldehyde for 1 hour. The hearts were sliced ( $400 \mu \mathrm{m}$ thick) with a Vibratome slicer (Technical Product International, Ltd., St. Louis, Mo.), Oxford Co.), refixed in the same solution for 2 hours, and washed in PBS followed by overnight incubation in the $\mathrm{X}$-gal solution. Sliced hearts with a positive assay for $\beta$-gal activity were used for histologic studies. Sections in paraffin $(4 \mu \mathrm{m})$ were stained with hematoxylin-eosin (HE). Cryostat sections $(6 \mu \mathrm{m})$ were mounted on poly-L-lysine-coated glass slides for immunohistologic staining. The sections were incubated for 30 minutes with PBS containing $1 \%$ bovine serum albumin, followed by overnight incubation at $4^{\circ} \mathrm{C}$ with phycoerythrin-conjugated anti-Thy-1.2 (T-lymphocyte marker) ${ }^{14}$ and fluorescein isothiocyanate-conjugated anti-Mac-1 (macrophage marker) ${ }^{15}$ monoclonal antibodies. Moreover, the sections with a positive assay for $\beta$-gal activity were refixed with $2.5 \%$ glutalal-

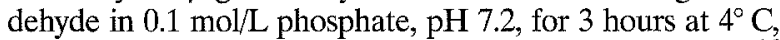
and postfixed with $1 \%$ osmium tetroxide for 1 hour at $4^{\circ} \mathrm{C}^{16}$ They were dehydrated in ethanol and embedded in Epon spurr resin (Polysciences, Inc., Warrington, Pa.). Ultrathin sections $(0.1 \mu \mathrm{m}$ thick) were cut with an ultramicrotome (Reichert Ultracut E; Reichert-Jung Optische Werke AG, Wien, Austria), stained in 4\% uranyl acetate for 20 minutes and observed under a JEM 1200EX electron microscope (JEOL Ltd, Tokyo, Japan). The hearts, which were injected with the final supernatant or the plasmid DNA used for rinsing the donor cells, were stained with $\mathrm{X}$-gal 7 days after the injection ( $n=10$ each).

\section{Results}

Adenovirus mediated gene transfer to cultured cardiomyocytes. Damage to the cultured cardiomyocytes by the infection procedure was examined by measuring $\mathrm{CK}$ release into the culture medium and by counting the numbers of living and dead cells. The median CK values in five samples were $6.9 \mathrm{IU} / \mathrm{L}$ (6.3 to $6.9 \mathrm{IU} / \mathrm{L})$ in $1000 \mathrm{MOI}, 2.3 \mathrm{IU} / \mathrm{L}(1.8$ to 2.8 $\mathrm{IU} / \mathrm{L})$ in $100 \mathrm{MOI}, 0.5 \mathrm{IU} / \mathrm{L}(0.5$ to $1.2 \mathrm{IU} / \mathrm{L})$ in 10 MOI, $1.2 \mathrm{IU} / \mathrm{L}(0.5$ to $1.2 \mathrm{IU} / \mathrm{L})$ in $1 \mathrm{MOI}, 0.5 \mathrm{IU} / \mathrm{L}$ ( 0.5 to $1.2 \mathrm{IU} / \mathrm{L})$ in $0.1 \mathrm{MOI}$, and $0.5 \mathrm{IU} / \mathrm{L}(0.2$ to 0.5 IU/L) in the control group. The median numbers of living cells in five samples were $3.1 \times 10^{5}(2.7$ to $\left.3.7 \times 10^{5}\right)$ in $1000 \mathrm{MOI}, 7.2 \times 10^{5}\left(6.2\right.$ to $\left.8.2 \times 10^{5}\right)$ in $100 \mathrm{MOI}, 6.9 \times 10^{5}\left(6.4\right.$ to $\left.8.0 \times 10^{5}\right)$ in $10 \mathrm{MOI}$, $6.9 \times 10^{5}\left(6.3\right.$ to $\left.7.6 \times 10^{5}\right)$ in $1 \mathrm{MOI}, 7.4 \times 10^{5}(6.9$ to $\left.8.0 \times 10^{5}\right)$ in $0.1 \mathrm{MOI}$, and $7.4 \times 10^{5}(6.2$ to $8.0 \times$ $\left.10^{5}\right)$ in the control group. The median numbers of dead cells in five samples were $37 \times 10^{4}$ (30 to $42 \times$ $\left.10^{4}\right)$ in $1000 \mathrm{MOI}, 5 \times 10^{4}\left(2\right.$ to $\left.6 \times 10^{4}\right)$ in 100 MOI, $2 \times 10^{4}\left(1\right.$ to $\left.4 \times 10^{4}\right)$ in 10 MOI, $2 \times 10^{4}(2$ to $\left.3 \times 10^{4}\right)$ in 1 MOI, $2 \times 10^{4}\left(1\right.$ to $\left.3 \times 10^{4}\right)$ in 0.1 MOI, and $2 \times 10^{4}\left(1\right.$ to $\left.4 \times 10^{4}\right)$ in the control group. To find a concentration with significant cytotoxity of the recombinant adenovirus, these results were tested by means of a Wilcoxon rank-sum test. In terms of CK value, 1000 and 100 MOI had a significant difference from the control group $(p<$ $0.05)$. In terms of the numbers of living and dead cells, $1000 \mathrm{MOI}$ had a significant difference from the control group $(p<0.05)$. These results indicated that the adenoviral infection at 10 MOI was safe with respect to cytotoxic effects. Almost all cells contracted throughout the culture period, even during the infectious period. One week after gene transfer, these cells formed confluent sheets and beat synchronously. Adenoviral infections apparently did not inhibit the electrical coupling that is essential for synchronous beating.

Gene transfer was assessed initially by X-gal staining. Virtually all cells in culture dishes showed blue color at more than $10 \mathrm{MOI}$ (Fig. 2, B). This means that $\beta$-gal was expressed in these cells. About half of the cultured cells at $1 \mathrm{MOI}$ and $5 \%$ to $10 \%$ at $0.1 \mathrm{MOI}$ had positive assays for $\beta$-gal. Because of these results regarding cytotoxity and efficiency, we used the adenovirus at 10 MOI to infect the cardiac cells in the following studies.

Histological examinations of the recipient hearts. Gross histologic examination of the host hearts was performed every 7 days after cell transplantation up to 12 weeks (Fig. 3, $A$ and $B$ ). Implanted cells showing blue color aligned themselves in circumferential arrays parallel to the host myocardium. Histologic analysis demonstrated that blue-stained cells were cardiomyocytes because of the cross striation in the cells (Fig. 3, C). HE staining also indicated that there was no myocardial fibrosis, capsule formation, nor infiltration of monocytes and leukocytes around the grafted cells. Immunohistochemical studies confirmed no inflammatory reactions (not shown). On the other hand, NIH 3T3 cells, which were incubated with the final supernatant used for rinsing the donor cells, had negative assays for $\beta$-gal activity. Hearts injected with the final supernatant or 


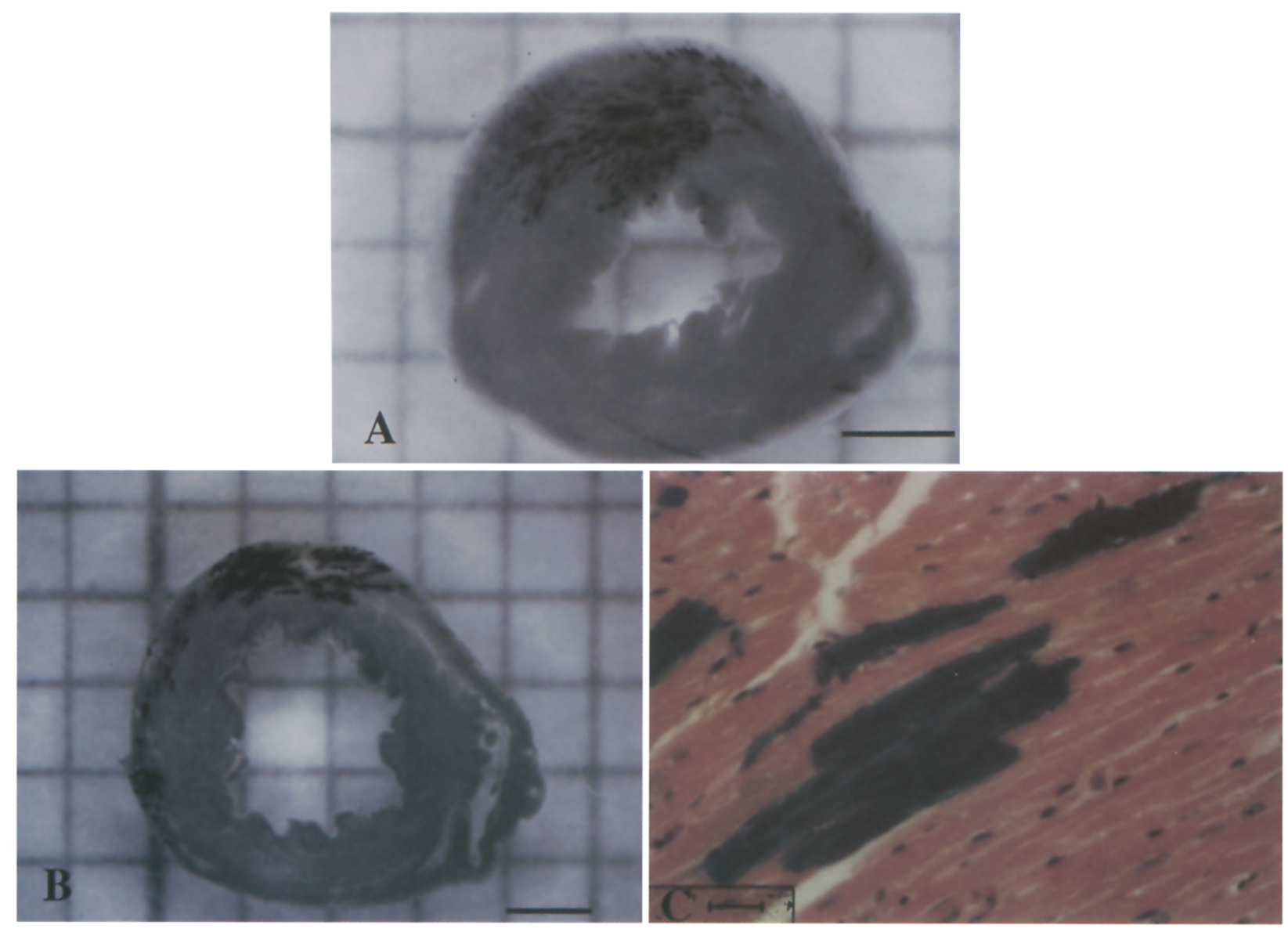

Fig. 3. X-gal and HE staining of hearts. Histologic examination of host hearts was carried out each week after implantation. A, Staining with X-gal on postoperative day 21. B, Staining with X-gal 12 weeks after implantation. C, Staining with HE on postoperative day 21. Blue cells aligned themselves along layers of host myocardium. Neither fibrous scars nor infiltrations of neutrofils were detectable within any section.

the plasmid DNA were not stained with X-gal. Moreover, blue-stained areas were not detected in the extracellular space of the myocardium throughout the experiment with this cell implantation. These results indicated that there were no adenoviruses within the injected solutions, and the cells expressing $\beta$-gal were not host cardiomyocytes taking up the naked plasmid DNA or $\beta$-gal released from the destroyed donor cells.

$\mathrm{X}$-gal is hydrolyzed by $\beta$-gal to generate galactose and soluble indoxyl molecules, which in turn are converted to insoluble indigo. Transmission electron microscopic (TEM) examination showed that donor and recipient cardiomyocytes were easily distinguished by the presence of electron-dense indigo, especially in the intermyofibrillar endoplasm. The grafted cells possessed abundant mitochondria and well-organized myofibrils (Fig. 4, $A$ ). These results indicate that the grafted fetal cardiomyocytes differentiated into mature cardiomyocytes in the host heart after cell implantation. At high magnification, the formation of intercalated disks between graft and host cardiomyocytes was observed. The connections consisted of desmosomes and gap junctions (Fig. 4, B). These intercalated disks between grafted and host cardiomyocytes were quite similar to those in normal adult hearts. These results demonstrate that the implanted cells formed functional syncytia with the host myocardium.

In all cases, surface electrocardiograms were recorded for 1 hour. The electrocardiographic patterns were indistinguishable between mice that underwent transplantation and control mice that did not (Fig. 5). No arrhythmias were detectable in the grafted group at anytime. As far as we tested, myocyte transplantation produced no adverse ef- 

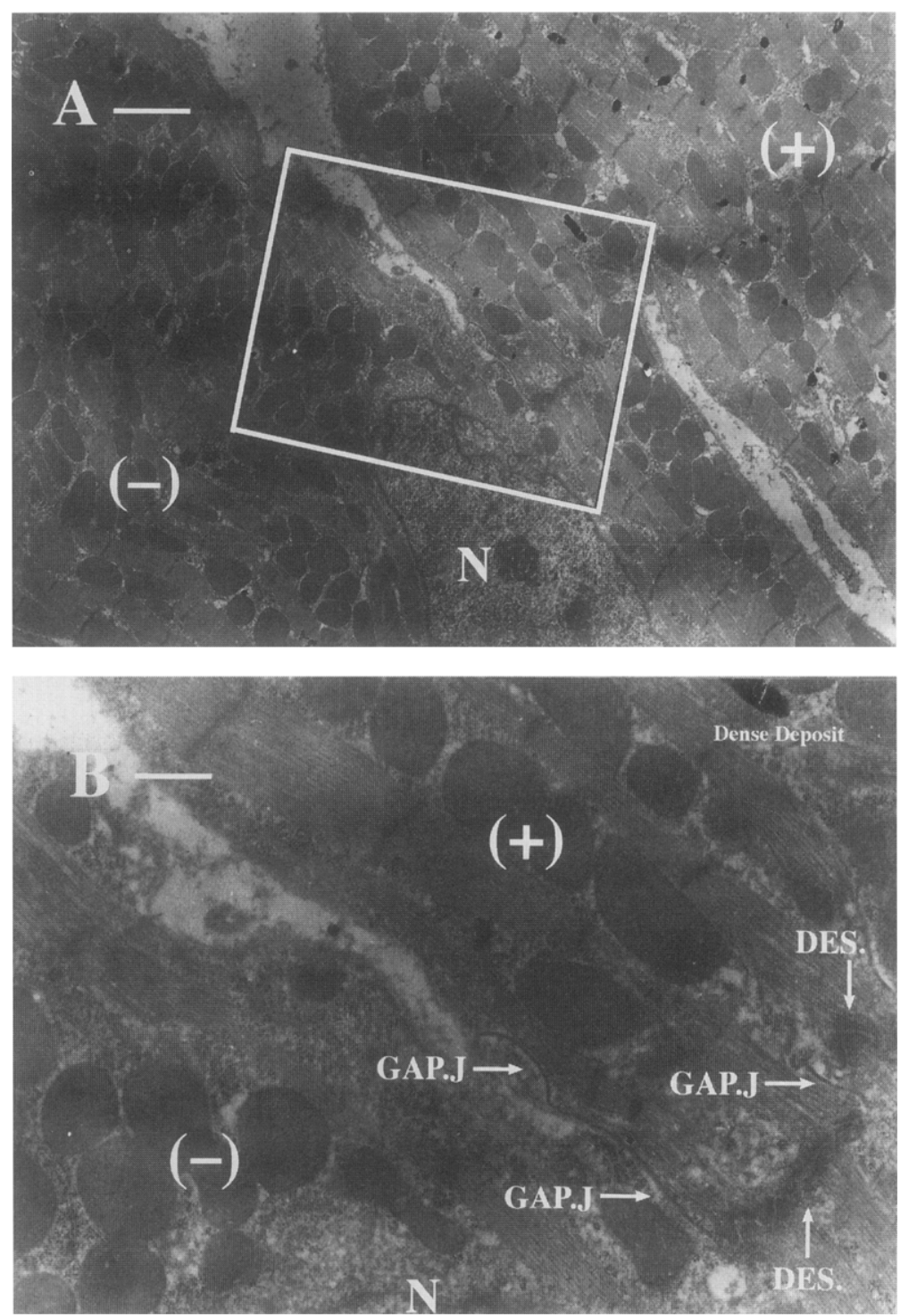

Fig. 4. TEM analysis from postoperative day 7 . Cells with $\beta$-gal possess electron-dense deposits in endoplasm. A, Grafted cells had abundant mitochondria, microtubles, and intercalated disks with host and other grafted cells. Bar indicates $2 \mu \mathrm{m}$. B, Desmosomes (DES.) and gap junctions (GAP.J) were clearly found in intercalated disks. Bar indicates $500 \mathrm{~nm}$. +, Grafted cardiomyocyte; -, host cardiomyocyte; $N$, nucleus.

fects on the electrical pathways of the host myocardium.

\section{Discussion}

The results presented here demonstrate for the first time that ex vivo genetically modified cardiomyocytes can be transplanted into the heart. We found that all primary fetal cardiomyocytes were transduced in vitro with the reporter gene without any damage by means of recombinant adenovirus, the implanted cardiac cells survived in the syngeneic host heart and expressed the exogenous gene in vivo for longer than 12 weeks, the graft formed gap junctions with the host ventricular myocytes or other grafted cells and differentiated to a mature phenotype, and no adverse effects in terms of electrocardiography or histologic examinations were detectable in this cellular transplantation procedure.

We selected an adenoviral vector as the gene transfer vehicle because of its high transfer efficacy. 


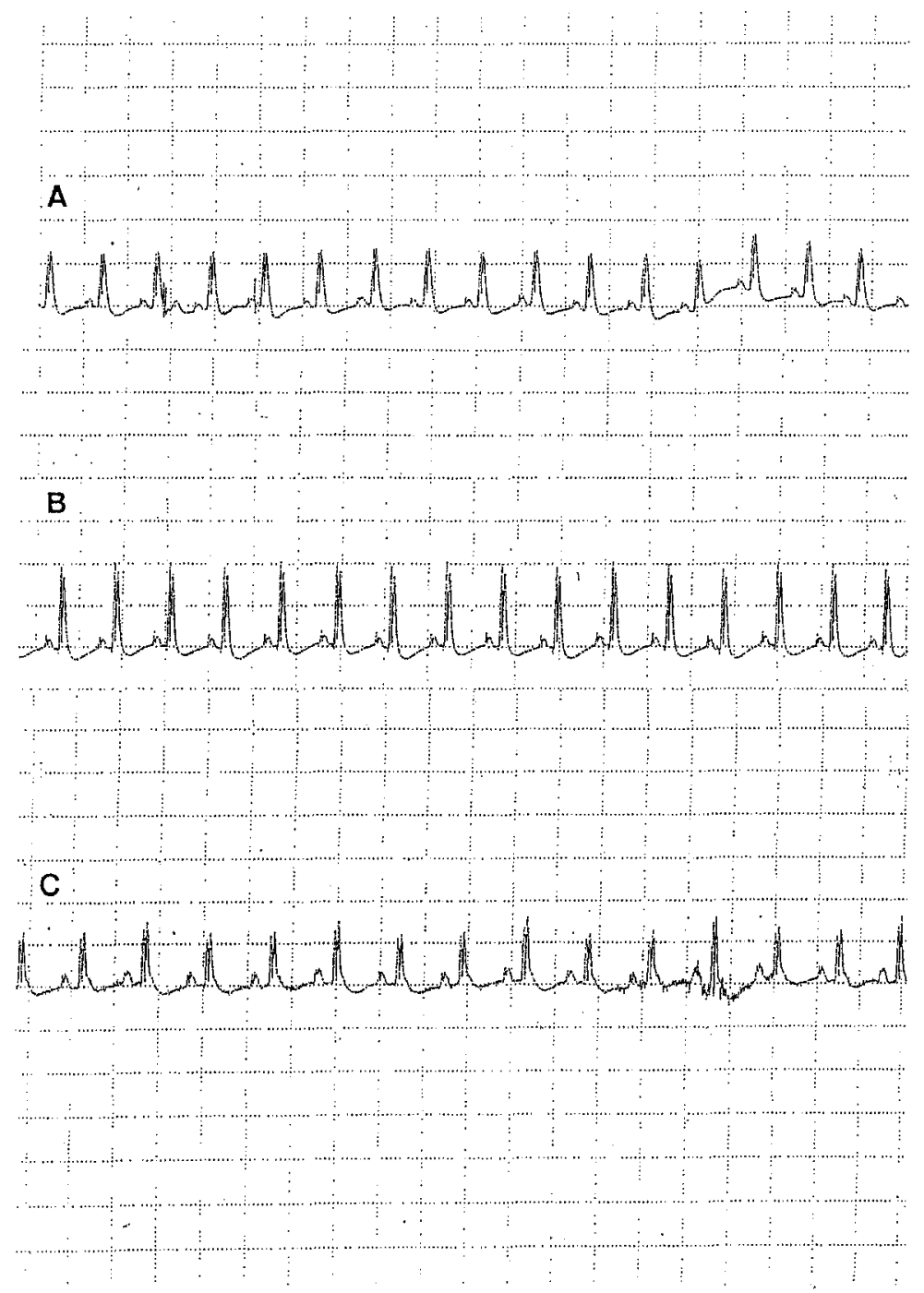

Fig. 5. Electrocardiograms of mice in transplanted and control groups. Electrocardiograms were recorded before mice in grafted group were killed for histologic and TEM examination. Recording speed was 100 $\mathrm{mm} / \mathrm{min}$. A, Preoperative electrocardiogram. B, Electrocardiogram at postoperative week 1. C, Electrocardiogram at postoperative week 12. No significant difference in electrocardiographic pattern was found between grafted and control groups. In addition, no arrhythmia was recorded in grafted group at any time.

In nonviral systems, the expression of transduced genes in cardiomyocytes is only $10 \%$ to $20 \%$, even under optimal conditions. ${ }^{17}$ We previously tried several retroviral vectors. Because primary cultures of cardiac cells cannot be maintained longer than 7 days without overgrowth of fibroblasts, the longterm culture and selection of gene-transduced cells cannot be carried out. For this reason, the efficacy of gene transfer was about $30 \%$, even with Transwell (Costar, Cambridge, Mass.). ${ }^{18}$ This study showed that adenovirus can infect virtually $100 \%$ of the cells and causes no damage to cultured cells at the MOIs tested here.

To rule out the possibility that native cardiomyocytes were stained with $\mathrm{X}$-gal, we examined the final supernatant used for rinsing the donor cardiomyocytes. Neither NIH 3 T3 cells incubated with the solution nor hearts injected with the solution were stained with X-gal. These results demonstrated that free viruses were not contained within the injected 
suspensions. The alternative hypothesis, that native cells were stained by the uptake of the reporter gene or $\beta$-gal released from the destroyed donor cells, is refuted by the following results. The naked plasmid containing $\beta$-gal gene injections did not make the host cells stain with X-gal within the hearts. Moreover, we could not find any blue-stained areas in the extracellular space of the hearts with grafted fetal cardiomyocytes. These facts strongly suggest that cells with positive assays for $\beta$-gal are not native cells, but donor cells.

This study revealed a long persistence of gene expression. Although adenovirus-mediated gene transfer is considerably more efficient than other systems of gene transfer, many earlier studies reported that the expression of the transduced gene products disappeared after 4 weeks. ${ }^{17-19}$ In neonatal mice, however, it has been reported that gene expression persisted for as long as 12 months after either intravenous or intramuscular (quadriceps) injection with recombinant adenovirus. ${ }^{20}$ Moreover, cell transplantation after in vitro gene transfer with adenovirus has not been previously reported. In this study, $\beta$-gal expression was observed for as long as 12 weeks after adenoviral infection. Although the mechanism of long-term gene expression is unclear, we speculate that the transient expression in the earlier reports ${ }^{17,19}$ resulted from the host immune response to adenovirus. In the study reported by Stradford-Perricaudet and colleagues, ${ }^{20}$ the animals injected with adenoviruses were neonates with an immature immune system. In our study, the host immune system seemed not to be stimulated against the adenoviruses because the donor cells were washed well enough to exclude adenoviruses in the extracellular space. This long-term expression of recombinant molecules can certainly be a major benefit for cellular transplantation.

Gap junctions between engrafted fetal cells and the host myocardium were demonstrated by TEM examination. Gap junctions are specialized regions composed of numerous intercellular low resistance channels in intercalated disks. ${ }^{21,22}$ They facilitate the passage of electrical activity, which is critical to the normal functioning of the heart. TEM analysis revealed further that grafted cardiomyocytes formed abundant intercalated disks, including gap junctions and desmosomes, with recipient myocytes. This result strongly suggests that grafted cardiomyocytes may contract synchronously with the host heart.

The grafted cells differentiated and adapted within the host heart. In TEM analysis, the engrafted cells were found to possess abundant mitochondria and transverse tubules. In fetal cardiomyocytes, these intracellular components are sparse. Moreover, in cellular transplantation to the heart, grafted cardiomyocytes must be oriented such that their contractile activity will contribute cardiac function. It has been reported that a mechanical tension induced orientation in a primary culture of adult rat cardiac myocytes. ${ }^{23}$ Cardiomyocytes cultured under conditions of oscillating tension tend to align themselves parallel to the direction of stretch. The force generated by the surrounding host myocardium might therefore influence the alignment of the grafted cells. The alignment of the implanted cells observed in this study may allow effective cooperation with the host myocardium. The differentiation and adaptation of the grafted cells are consistent with previous reports. ${ }^{7}$ These results suggest that the grafted cells may be able to contribute to the host overall cardiac function. The absence of detectable arrhythmia is important to cardiac cell transplantation. Mechanical stimuli, myocardial infarction, and inflammation can cause lethal arrhythmias. In our experiments, no pathologic changes were detectable on histologic analysis, and the absence of arrhythmia was confirmed in the grafted mice.

Our study demonstrates that in vitro gene-transducted cardiomyocytes can be transplanted successfully into the hearts of adult syngenic recipient mice, and grafted myocytes can form the gap junction with neighbor myocytes. A recent study also showed that fetal cardiomyocytes of transgenic mice with a $\beta$-gal transgene formed intercalated disks with host cardiomyocytes after cell transplantation. ${ }^{7}$ In that study, the $\beta$-gal gene was used only as a marker, and the grafted cells were not free from fibroblasts. In our study, we used $\beta$-gal as a reporter gene, but other genes could easily be introduced for therapeutic purposes. Because it is crucial in cell transplantation to obtain pure population of implanted cells, we attempted to purify the donor myocytes as much as possible by removing the fibroblasts, as described in the Methods section. Although we used fetal cardiomyocytes as donor cells, fetal cell transplantation engenders an ethical quandary. Myoblast transplantation to the heart ${ }^{5,6}$ and the skeletal muscle ${ }^{24,25}$ has shown promising results. It is unknown at present, however, whether the myoblasts can differentiate into mature cardiomyocytes within the heart and incorporate with the host myocardium. 
In the future, genetically engineered cardiac cell transplantation may become a realistic therapeutic modality for acute or chronic heart failure with significant myocyte loss.

We thank Drs. Osam Mazda (Kyoto Prefectural University of Medicine, Department of Microbiology, Kyoto, Japan) and Wilfred T. V. Germeraad (Children's Hospital Los Angeles, Department of Pathology) for helpful discussions, Dr. Norio Kurumatani (Nara Medical College, Department of Public Health, Nara, Japan) for statistical procedure, and Mr. Masayuki Saito (Nihon Kohden Co., Japan) for excellent technical assistance.

\section{REFERENCES}

1. Koh GY, Klug MG, Soonpaa MH, Field LJ. Differentiation and long-term survival of $\mathrm{C} 2 \mathrm{C} 12$ myoblast grafts in heart. J Clin Invest 1993;92:1548-54.

2. Field LJ. Atrial natriuretic factor SV40 $\mathrm{T}$ antigen transgenes produce tumors and cardiac arrhythmias in mice. Science 1988;239:1029-33.

3. Delcarpio JB, Lanson NA Jr, Field LJ, Claycomb WC. Morphological characterization of cardiomyocytes isolated from a transgenic mouse atria (AT-1 cells). Circ Res 1991; 69:1591-600.

4. Lanson NA Jr, Glemboiski CC, Steinhelper ME, Field LJ, Claycomb WC. Gene expression and atrial natriuretic factor processing and secretion in cultured AT-1 cardiac myocytes. Circulation 1992;85:1835-41.

5. Marelli D, Desrosiers C, El-Alfy M, Kao RL, Chiu RC. Cell transplantation for myocardial repair: an experimental approach. Cell Transplant 1992;1:383-90.

6. Yoon PD, Kao RL, Magovern GJ. Myocardial regeneration: transplanting satellite cells into damaged myocardium. Texas Heart Inst J 1995;22:119-25.

7. Soonpaa MH, Koh GY, Klug MG, Field LJ. Formation of nascent intercalated disks between grafted fetal cardiomyocytes and host myocardium. Science 1994;264:98-101.

8. Saito I, Oya Y, Yamamoto K, Yuasa T, Shimojo H. Construction of nondefective adenovirus type 5 bearing a 2.8 kilobase hepatitis B virus DNA near the right end of its genome. J Virol 1985;54:711-9.

9. Niwa H, Yamamura K, Miyazaki J. Efficient selection for high-expression transfectants with a novel eukaryotic vector. Gene 1991;108:193-200.

10. Kanegae Y, Makimura M, Saito I. A simple and efficient method for purification of infectious recombinant adenovirus. Jpn J Med Sci Biol 1994;47:157-66.

11. Precious B, Russel WC. Growth, purification and titration of adenoviruses. In: Mahy BM, editor. Virology: a practical approach. 1st ed. Oxford, England: IRL Press, 1985:193205.

12. Goshima K. Ouabain-induced arrhythmias of single iso- lated myocardial cells and cell clusters cultured in vitro and their improvement by quinidine. J Mol Cell Cardiol 1977;9:7-23.

13. Yamashita N, Nishida M, Hishida S, Kuzuya T, Hori M, Taniguchi $\mathbf{N}$, et al. Induction of manganese superoxide dismutase in rat cardiac myocytes increases tolerance to hypoxia 24 hours after preconditioning. J Clin Invest 1994; 94:2193-9.

14. Marshak-Rothstein A, Fink P, Gridley T, Raulet DH, Beven MJ, Gefter MI. Properties and applications of monoclonal antibodies directed against determinants of the Thy- 1 locus. J Immunol 1979;122:2491-9.

15. Springer T, Galfre G, Secher DS, Milstein C. Mac-1: a macrophage differentiation antigen identified by monoclonal antibody. Eur J Immunol 1979;9:301-6.

16. Colombo MP, Lombardi L, Stoppacciaro A, Melani C, Parenza M, Bottazzi B, et al. Granulocyte colony-stimulating factor (G-CSF) gene transduction in murine adenocarcinoma drives neutrophil-mediated tumor inhibition in vivo: neutrophils discriminate between G-CSF-producing and G-CSF-nonproducing tumor cells. J Immunol 1992; 149:113-9.

17. Kass-Eisler A, Falck-Pedersen E, Alvira M, Rivera J, Buttrick PM, Wittenberg BA, et al. Quantitative determination of adenovirus-mediated gene delivery to rat myocytes in vitro and in vivo. Proc Natl Acad Sci U S A 1993;90:11498-502.

18. Germeraad WT, Asami N, Fujimoto S, Mazda O, Katsura $Y$. Efficient retrovirus-mediated gene transduction into murine hematopoietic stem cells and long-lasting expression using a transwell coculture system. Blood 1994;84: $780-8$

19. Guzman RJ, Lemarchand P, Crystal RG, Epstein SE, Finkel T. Efficient gene transfer into myocardium by direct injection of adenovirus vectors. Circ Res 1993;73:1202-7.

20. Stratford-Perricaudet LD, Makeh I, Perricaudet M, Briand $P$. Widespread long-term gene transfer to mouse skeletal muscles and heart. J Clin Invest 1992;90:626-30.

21. Beyer EC, Paul DL, Goodenough DA. Connexin43: a protein from rat homologous to a gap junction protein from liver. $\mathrm{J}$ Cell Biol 1987;105:2621-9.

22. Fishman GI, Spray DC, Leinwand LA. Molecular characterization and functional expression of the human cardiac gap junction channel. J Cell Biol 1990;111:589-98.

23. Samuel JL, Vandenburgh HH. Mechanically induced orientation of adult rat cardiac myocytes in vitro. In Vitro Cell Dev Biol 1990;26:905-14.

24. Barr E, Leiden JM. Systemic delivery of recombinant proteins by genetically modified myoblasts. Science 1991;254: 1507-9.

25. Ragot T, Vincent N, Chafey P, Vigne E, Gilgekrantz H, Couton $D$, et al. Efficient adenovirus-mediated transfer of a human minidystrophin gene to skeletal muscle of mdx mice. Nature 1993;361:647-50. 